Voix et Images

voixetimages

\title{
Poésie minimale (?) de l'Alberta au Québec
}

\section{Noël Audet}

Volume 4, numéro 2, décembre 1978

Guy Lafond

URI : https://id.erudit.org/iderudit/200162ar

DOI : https://doi.org/10.7202/200162ar

Aller au sommaire du numéro

Éditeur(s)

Les Presses de l'Université du Québec

ISSN

0318-9201 (imprimé)

1705-933X (numérique)

Découvrir la revue

Citer cet article

Audet, N. (1978). Poésie minimale (?) de l'Alberta au Québec. Voix et Images, 4(2), 334-337. https://doi.org/10.7202/200162ar d'utilisation que vous pouvez consulter en ligne.

https://apropos.erudit.org/fr/usagers/politique-dutilisation/ 


\section{Poésie minimale (?) de l'Alberta au Québec}

II n'est pas facile, à qui reçoit ou se procure une demi-douzaine de recueils, de continuer à tracer son chemin relatif dans ce champ disparate. Mais cela nous permet à tout le moins de constater qu'il se publie de tout, au pays (je ne dis pas n'importe quoi) dans le genre dit poétique, du sonnet classique aux bouts rimés en parfaite platitude. Et encore, il manque dans mon coup de filet les poètes des "Herbes rouges" qui possèdent de plus en plus leur langage et leur univers particuliers.

De Bernard Courteau, les Temples de la nuit ', recueil de plus de deux cents sonnets carrés, sonnant, posés bien verticalement sur chaque page, beaux il faut le dire - et poétiques.

L'oiseau strie l'ocre aimé de son cri fulgurant

Comme l'espace s'ouvre et ruisselle en ses sombres

Safrans. Crépusculaire, il se violace d'ombres

Et renaît par les vents, secret et transparent. (P. 3) 
Mais comment est-ce possible d'écrire en 1978 autant de sonnets et faire ainsi mentir ceux qui prétendent qu'il y a homologie entre les formes littéraires et les formes sociales? Cette nostalgie des contraintes prosodiques rejette-t-elle l'histoire récente (qui serait confondue avec la mode) au profit d'une autre histoire jugée plus essentielle? La question mériterait une recherche approfondie et peut-être une réponse toute autre.

Dans l'Astrolabe de Marcel Nadeau, on lit de beaux poèmes encore, mais faits de petits riens. Comme une poésie minimale, courant du trait le plus fin sur la page, disparaissant tout à coup par en haut dans «le destin / de l'ange".

\section{Itinéraire}

Refus du regret envers d'une journée

Joie

Je pose l'énigme du temps (p. 63)

Je ne conteste pas la poésie de ces dessins chinois, j'en constate la fragilité et le refus de plonger dans l'épaisseur du monde.

Par contraste et peut-être en soi, les Néons las ${ }^{3}$ de Lucien Francœur sont une pure merveille coulant de source et mêlant le sublime au trivial dans un même vers, libre. Invention de mots savants aussi bien qu'utilisation de mots joual, tours syntaxiques sur mesure, sa thématique s'étend de l'amour au politique en passant par la critique des littérateurs et des abscons :

hermétisme enténébré

dans des tirages de nains

[...]

faux parnassiens fabriquants de rien

vous êtes des pushers de crayons

Rien n'est innomable comme le montrent certains titres: «Panique dans l'urètre", "Manucure Anne Hébert", “Kafka est là Camus est vu», «Polaroïd d'une érection », etc., et ce beau poème d'amour écrit par une sorte de Baudelaire de faubourg :

Violande venaison accours ma vlimeuse ma yummeuse ma fleur de peau ma yoyo

fille hallucinante tu déteins

tu m'atteins d'un bout à l'autre

ta chaleur assume et arrime mes maux

vers ton rire qui court dans mon dos

ton hilarité chamarrée colore mes haut-parleurs

ne t'éloigne pas trop de ma queue ma moqueuse

(p. 13) 
Le ton est vrai, le jeu des signifiants sonne juste et la poésie surgit par, ou malgré, le trivial et la langue familière. Et nous sommes aux antipodes des deux recueils ci-haut mentionnés. Je terminerai mes quelques remarques sur ce recueil fort intéressant, plein de fureur et d'inventions, en citant des vers qui constituent un art poétique et nous font songer à $G$. Miron et à la difficulté d'écrire au Québec :

j'entrevois mon dialecte pris au collet
je vois chaud j'avoir peur
ma férocité littéraire s'effiloche
alors je brame je barrie je hurle je bave
artiste ficelé dans une guêpière ethnique
j'allonge ma honte au bagne du spleen

De l'Alberta, Guy Pariseau publie l'Envers des jours ${ }^{4}$, un joli recueil de jolies choses en vers libres mais avec cette particularité qu'il y a presque toujours une assonance à la rime. On est poète un peu comme d'autres vont à la messe une fois la semaine ou portent l'aigrette au chapeau.

Poème

Pour écrire un poème

II suffit de bien peu

On peut dire «Je t'aime"

Ou " Je t'aime encore mieux!"

[sans pagination]

Cela n'étant qu'un programme de chanson, je dirai qu'il faut dire plus et le dire mieux pour retenir un lecteur de poésie.

Poésie minimale encore que ce recueil de J. R. L. Léveillé intitulé CEuvre de la première mort ${ }^{5}$, mais dans un autre sens. En effet, sauf dans la section intitulée «Figure " et dans quelques autres pages où l'auteur réduit son poème jusqu'à n'écrire plus qu'un seul mot: «scène» (p. 63), cette poésie est plutôt dense, très ouvragée, sur les traces d'Edgar Poe et de Mallarmé. Le signifiant s'y déploie dans des redondances pour la pure jouissance des sonorités. L'auteur semble un admirateur de Barthes à qui il dédie un poème-critique. Témoins de cette jouissance phonématique un poème constitué d'un seul vers : "énigme d'espace dieu contre yeux faute de fatal feu » (p. 37).

On retrouve les mêmes jeux-déplacements syntaxiques et une grande charge symbolique dans le moins de mots possible. C'est plaisant comme le plaisir du texte.

Avec Marcel Bélanger et ses Fragments paniques ${ }^{6}$ on passe aux grandes orgues du poème en prose. A la fois chargés de poésie et pleins d'idées, ces poèmes s'écartent des recueils précédents du même auteur par une volonté de dire sans détours ce qui l'interpelle. II s'agit d'une espèce de bilan poétique, de retour sur la motivation de l'écriture, et ce, sans renoncer à la puissance des images. 
Jadis subjugué par une parole trop faste, j'oubliai la terre - qui pourrait m'en blâmer? - pour rêver d'un vol pur ne retenant de l'oiseau qu'une ligne mouvante et mauve. (p. 29)

Mais quand ce regard critique se tourne vers l'autre, il s'y promène d'énormes pans de désespoir et un appel à la révolte: “Maintenant il est trop tard pour vous comme pour moi » (p. 63), "N'attendez pas de moi que je traduise l'obscurité de votre visage... (p. 66), «mettre le feu aux poutres, faire du texte un baril de poudre, porter vos fièvres jusqu'à la déflagration 》 (p. 67).

Les résonances politiques y sont d'ailleurs virulentes:

Mais... perclus d'humiliations, ils nous ont appris la reptation; ils nous somment de marcher droit en nous suspendant par la peau du dos. Ils nous ont tranché la langue et nous bafouillons nos plus chères douleurs. II nous ont percé les yeux pour mieux mirer notre aveuglement. (p. 72)

Bref un recueil intéressant à plusieurs titres.

Voilà pour le petit tour de poésie, d'Edmonton à Québec, en passant par Trois-Rivières. Toutes les formes coexistent en toute liberté, ce qui ne conduit pas nécessairement à l'excellence... Mais à chacun sa voix!

Noël Audet

1. Les Temples de la nuit, Montréal, Éditions Émile-Nelligan, 1978.

2. Astrolabe, Trois-Rivières, Éditions du Bien public, 1977.

3. Les Néons las, Montréal, L'Hexagone, 1978.

4. L'Envers des jours, Edmonton, Éditions de l'églantier, 1978.

5. CEuvre de la première mort, Saint-Boniface, Les éditions du blé, 1977.

6. Fragments paniques, Sainte-Foy, Les éditions parallèles, 1978. 